\title{
Microstructure and Enhanced Properties of Copper-Vanadium Nanocomposites Obtained by Powder Metallurgy
}

\author{
Yong Wang ${ }^{1}$, Jinguo Wang ${ }^{1}$, Haohao Zou ${ }^{2}$, Yutong Wang ${ }^{2}$ and Xu Ran ${ }^{2, *}$ \\ 1 Key Laboratory of Automobile Materials, Ministry of Education, Department of Materials Science and \\ Engineering, Jilin University, No. 5988 Renmin Street, Changchun 130025, China; gxgy9406@163.com (Y.W.); \\ mason1006@163.com (J.W.) \\ 2 Key Laboratory of Advanced Structural Materials, Ministry of Education, \\ Changchun University of Technology, No. 2055 Yanan Street, Changchun 130012, China; \\ haoozou@163.com (H.Z.); wyt9408@163.com (Y.W.) \\ * Correspondence: ranxu@ccut.edu.cn; Tel.: +86-431-85716426
}

Received: 11 December 2018; Accepted: 18 January 2019; Published: 22 January 2019

\begin{abstract}
Cu}-2.4$ wt.\%V nanocomposite has been prepared by mechanical alloy and vacuum hot-pressed sintering technology. The composites were sintered at $800{ }^{\circ} \mathrm{C}, 850{ }^{\circ} \mathrm{C}, 900{ }^{\circ} \mathrm{C}$, and $950{ }^{\circ} \mathrm{C}$ respectively. The microstructure and properties of composites were investigated. The results show that the $\mathrm{Cu}-2.4$ wt.\%V composite presents high strength and high electrical conductivity. The composite sintered at $900{ }^{\circ} \mathrm{C}$ has a microhardness of $205 \mathrm{HV}$, a yield strength of $404.41 \mathrm{MPa}$, and an electrical conductivity of 79.5\% International Annealed Copper Standard (IACS); the microhardness and yield strength reduce gradually with the increasing consolidation temperature, which is mainly due to the growth of copper grain size. After sintering, copper grain size and V nanoparticle both maintain in nanoscale; the strengthening mechanism is related to grain boundary strengthening and dispersion strengthening, while the grain boundary strengthening mechanism plays the most important role. This study indicates that the addition of small amounts of $V$ element could enhance the copper matrix markedly with the little sacrifice of electrical conductivity.
\end{abstract}

Keywords: copper; nanocomposite; high strength; conductivity; strengthening mechanism

\section{Introduction}

In recent years, with the rapid development of the aerospace industry, micro-electronics, communication, medicine, life sciences, and so on, there is a high request for copper alloy's various indicators and the capacity of adapting to an environment, such as possessing high strength and high conductivity simultaneously [1-4]. It is hard to improve the strength of copper, which always comes at the price of conductivity reduction. How to enhance the strength sharply while keeping the high conductivity of copper as far as possible becomes the important issue in the development of the modern copper processing industry [5]. One of the most common methods to improve the mechanical properties of copper is to add solid solution elements, such as Ti [6], Ni [7], Si [8], and Cr [9] etc. Although this sort of alloy elements could endow copper alloys with higher strength, their conductivity is typically reduced. The strength of some could be more than $1000 \mathrm{MPa}$, but their conductivity is less than $20 \%$ IACS. Therefore, new copper alloys with superior mechanical properties and high conductivity still need to be researched.

It is common knowledge that the alloy elements dissolving in or reacting with the matrix could reduce the conductivity of the matrix. So the element that is mutually insoluble or slightly soluble with copper in the solid state has a uniquely high combination of mechanical properties, electric 
conductivity, and thermal conductivity, such as Fe [10], Ag [11,12], and $\mathrm{Nb}$ [13] etc. Among them, the $\mathrm{Cu}-\mathrm{Nb}$ system has the best combination of properties. Lei et al [14] prepared nanocrystalline $\mathrm{Cu}-10 \mathrm{wt} . \% \mathrm{Nb}$ alloy with high strength and high conductivity by mechanical alloy method (MA) and vacuum hot-pressed sintering technology. The tensile strength of as-received sample is $1102 \mathrm{MPa}$ while the conductivity is $57 \%$ IACS. Compared with $\mathrm{Nb}, \mathrm{V}$ possesses higher hardness, low density, and low activation while it also has no intermediate intermetallic phases and a minimum value of mutual solubility in copper [15]. Therefore, $\mathrm{V}$ was chosen to enhance copper matrix in this study. Unfortunately, few studies on $\mathrm{Cu}-\mathrm{V}$ alloy have been reported and most of these researches mainly focus on the $\mathrm{Cu}-\mathrm{V}$ alloy wire by cold drawing and $\mathrm{Cu}-\mathrm{V}$ multilayer films [16-19]. The vanadium fibre reinforced copper matrix wire presents very high strength, but like the $\mathrm{Nb}$ and $\mathrm{Ag}$ fibre, the $\mathrm{V}$ fibre would be divided and spheroidality, which could cause a sharply drop in strength. Therefore, researching the properties of $\mathrm{Cu}-\mathrm{V}$ nanocomposites is very necessary and the work on this aspect hasn't been reported yet.

In this study, Cu-2.4 wt.\%V nanocomposites were prepared by MA and vacuum hot-pressed sintering technology. The main purpose of this job is to evaluate the effect of consolidation temperature on the microstructure and properties and discuss the strengthening mechanism of composites systematically.

\section{Materials and Methods}

The $\mathrm{Cu}-\mathrm{V}$ nanocomposites with $2.4 \mathrm{wt}$.\% V were fabricated by MA and vacuum hot-pressed sintering technology. The raw materials used in this study were ultra-fine copper powder $(4-7 \mu \mathrm{m}$, the purity $\geq 99.9 \%$ ) and vanadium powder $(10-15 \mu \mathrm{m}$, the purity $\geq 99.6 \%)$. The MA process was carried in a dual-tank three dimensional oscillating high energy ball mill (home-made) with $\mathrm{Cr}_{12} \mathrm{MoV}$ containers and $\mathrm{GCr}_{15}$ bearing steel balls under an argon atmosphere. The ball-to-powder weight ratio was 10:1; rotation speed was $370 \mathrm{r} / \mathrm{min}$; the duration of the ball mill was $60 \mathrm{~h}$ and acetone was used as process control agent. The milled $\mathrm{Cu}-\mathrm{V}$ powder was annealed in a hydrogen atmosphere at $560{ }^{\circ} \mathrm{C}$ for $1 \mathrm{~h}$ to reduce the inner strain and oxygen in $\mathrm{Cu}-\mathrm{V}$ powder. Then the annealed powder was sintered by vacuum hot pressing sintering under a load of $50 \mathrm{MPa}$ for $2 \mathrm{~h}$ at $800^{\circ} \mathrm{C}, 850^{\circ} \mathrm{C}, 900{ }^{\circ} \mathrm{C}$, and $950{ }^{\circ} \mathrm{C}$ respectively.

The density was measured by the Archimedes method; X-ray diffraction (XRD) profiles of the samples were analysed using a DMAX2000 X-ray diffractometer (Rigaku Corporation, Beijing, China) with $\mathrm{CuK} \alpha$ radiation and the scans of $2 \theta$ were taken from $40^{\circ}$ to $80^{\circ}$; the microstructure was observed by the EIPHOTO NIKON 300 optical microscope (OM) (Nikon, Shanghai, China), JMS-5500LV scanning electron microscope (SEM) (JMS Corporation, Shenzhen, China), and high resolution transmission electron microscopy (HRTEM) (FEI Corporation, Shanghai, China); TEM samples were prepared using 980 Microconcave grinder and Gatan691 ion milling (GATAN, Shanghai, China). The micro-hardness of the samples was measured on a FM-700 microhardness tester (FT Corporation, Xi'an, China) using a load of $25 \mathrm{gf}$ and a holding of $15 \mathrm{~s}$. The electrical conductivity of the samples was measured on a sigma 2008 digital eddy metal conductance meter (Xiamen tianyan instrument co., LTD., Xiamen, China) at the room temperature. The strength of the samples was tested on a WDW-200 tensile testing machine (Shanghai precision instrument co., LTD., Shanghai, China) using a strain rate of $0.2 \mathrm{~mm} / \mathrm{min}$. The tested samples were in the form of a cylindrical pin with $3 \mathrm{~mm}$ of diameter and $6 \mathrm{~mm}$ of length.

\section{Results}

\subsection{Phase and Morphology of Samples}

The image of $\mathrm{Cu}-\mathrm{V}$ composite powder after ball milling for $60 \mathrm{~h}$ is shown in Figure 1a. The powder particles show subsphaeroidal and some big particles are found which is due to the welding-on. The particle size distribution is shown in Figure 1b. Mainly, the size of the particle is about several microns and its average size is $4.14 \mu \mathrm{m}$. Figure 1c shows the energy dispersive spectrometer (EDS) 
result from certain particles. It can be observed that $\mathrm{V}$ peaks are very weak, which is because vanadium addition is small. EDS (point scanning) was carried out on several particles selected randomly. Three results of them are displayed in Table 1 . The mass fractions of vanadium in copper are $2.51 \%$, $2.12 \%$, and $2.24 \%$ respectively and very close to $2.4 \%$ (the raw material ratio), which indicates that the distribution of vanadium in copper is uniform after $60 \mathrm{~h}$ ball milling.
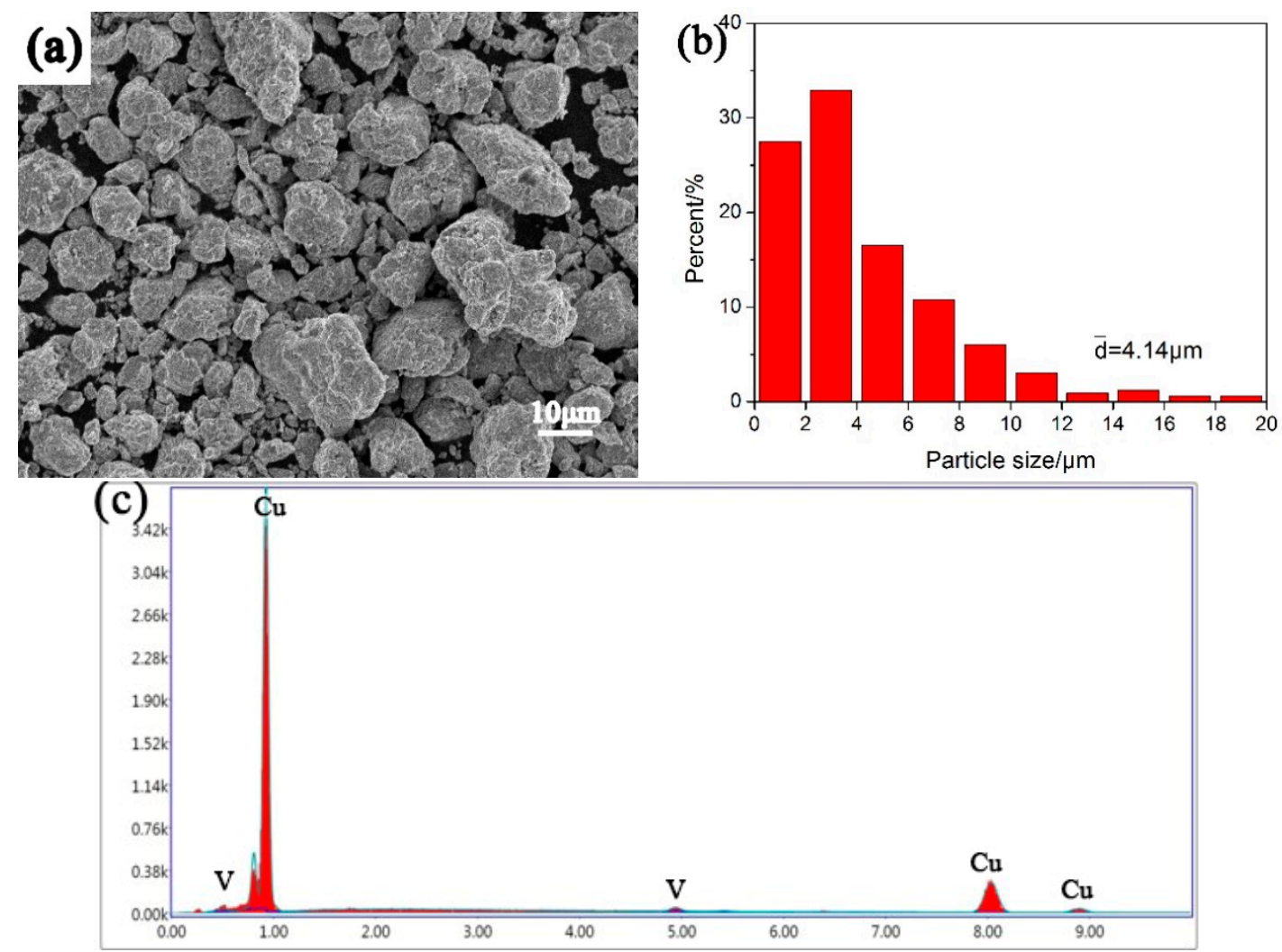

Figure 1. Scanning electron microscope (SEM) image (a) and the size distribution; (b) of the $\mathrm{Cu}-\mathrm{V}$ composite power; (c) the energy dispersive spectrometer (EDS) result (point scanning) from certain particles; the " $\mathrm{k}$ " on $\mathrm{y}$-axis means thousand.

Table 1. V content of selected particles.

\begin{tabular}{ccc}
\hline Sample & Mass (\%) & Atom (\%) \\
\hline 1 & 2.51 & 3.11 \\
2 & 2.12 & 2.62 \\
3 & 2.24 & 2.76 \\
\hline
\end{tabular}

To research the existential state of vanadium in copper, XRD analysis was performed on the composite powders after different milling times. The result is shown in Figure 2a. It can be distinctly seen that the peak of copper become weak and wide with the ball milling process, which is due to the grain refining of copper. Furthermore, it can also be found that the $\mathrm{Cu}$ peaks move towards low angles with ball milling process (the insert in Figure 2a). Because vanadium addition is small, the peak of vanadium is very weak and only can be detected in composite powders milled for below $10 \mathrm{~h}$ and then disappears gradually with the ball milling process. The lattice parameters of copper at different milling times are recorded and shown in Figure 2b. In a certain duration of ball milling, the lattice parameter of copper increases with the ball milling process $(0-40 \mathrm{~h})$ and then decreases somewhat, which indicates that vanadium dissolves into copper during the ball milling process. The atomic radius of vanadium $(0.132 \mathrm{~nm})$ is slightly larger than copper $(0.128 \mathrm{~nm})$. When vanadium atoms dissolve into the copper lattice, the copper lattice will expand, which results in the increase of copper lattice 
parameter and the lattice distortion of copper. As for the later decrease of the copper lattice parameter, it is widely believed today that the reason for this phenomenon is that supersaturated vanadium in copper precipitates out due to the temperature rise after a long time ball milling [20]. From the XRD results, there is no obvious $\mathrm{CuO}$ peak, which also indicates that the oxygen contamination is little during the ball milling process.
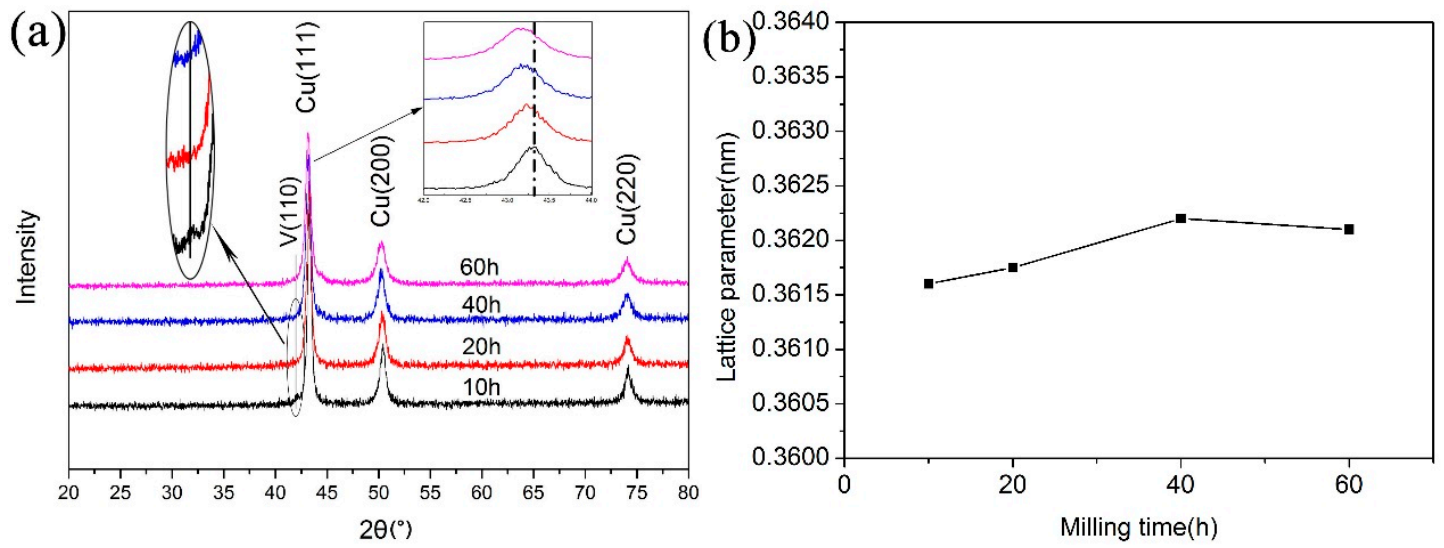

Figure 2. X-ray diffraction (XRD) patterns of $\mathrm{Cu}-\mathrm{V}$ composite powder (a) and the lattice parameter of copper at different milling time (b).

After ball milling, the composite powders were sintered by vacuum hot pressing at a load of $50 \mathrm{MPa}$ for $2 \mathrm{~h}$ at different temperature. The variation of relative density and the corresponding SEM images of the composites versus sintering temperature is shown in Figure 3. It can be seen that the relative density of composite sintered at $800{ }^{\circ} \mathrm{C}$ is about $88 \%$, whereas an increase of the consolidation temperature to $950{ }^{\circ} \mathrm{C}$ lead to a density of $97 \%$. In the case of the sample sintered at $800{ }^{\circ} \mathrm{C}$, numerous pores can be found. When the sintering temperature increases to $950{ }^{\circ} \mathrm{C}$, few pores can be detected, which is related to the higher density.

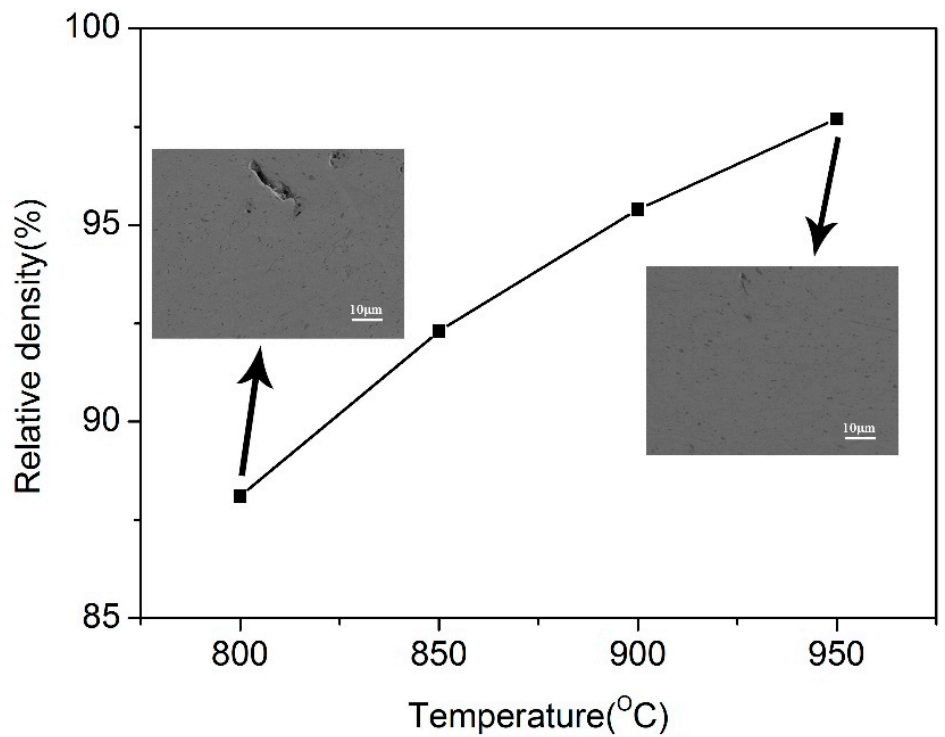

Figure 3. The change of relative density of composites with the consolidation temperatures. In the inset, SEM images show the microstructure of the composite sintered at $800{ }^{\circ} \mathrm{C}$ (left) and $950{ }^{\circ} \mathrm{C}$ (right).

Figure 4 shows the SEM images of composites sintered at different temperature. The dark grey particles in the matrix are V nanoparticles, which can be testified by EDS shown in Figure 4e. $\mathrm{V}$ nanoparticles are distributed in the copper matrix with a very wide size range after sintering. 
Nevertheless, there is still an amount of $\mathrm{V}$ nanoparticles which are too small to be detected by SEM (the TEM image can verify it shown in later), and only the larger part of $\mathrm{V}$ particles can be observed. With the increase of sintered temperature, the quantity of coarse V particles goes up. Therefore, the higher sintering temperature can result in the coarsening of V particles and copper crystal grain, but lower temperature is not good for the densification of composites. From the EDS result, it can be found that a small quantity of Fe is detected, which is introduced during the ball milling process.

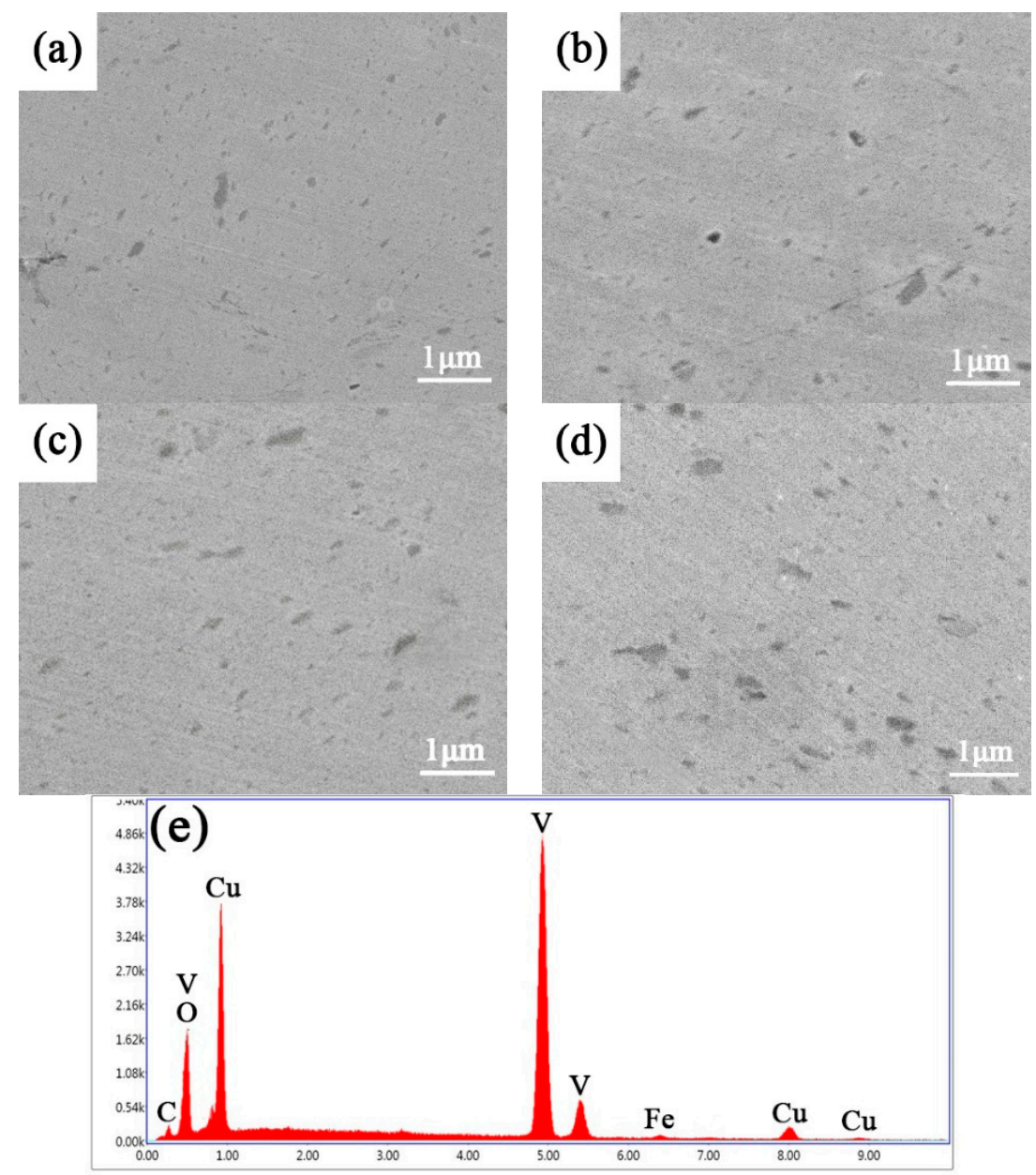

Figure 4. SEM images of $\mathrm{Cu} / \mathrm{V}$ composites sintered at different temperature: (a) $800{ }^{\circ} \mathrm{C}$; (b) $850{ }^{\circ} \mathrm{C}$; (c) $900^{\circ} \mathrm{C}$; (d) $950^{\circ} \mathrm{C}$; (e) EDS result of selected V particle in (d); the " $\mathrm{k}$ " on y-axis means thousand.

Figure 5a shows the TEM image of microstructure of composite sintered at $900{ }^{\circ} \mathrm{C}$ for $2 \mathrm{~h}$. It can be seen that the copper matrix is showing a coarse structure and the average copper crystal grain is larger than $100 \mathrm{~nm}$. Several big V particles are detected which are about several hundred nanometers in size and the interface of $\mathrm{V}$ and $\mathrm{Cu}$ is tight and no gap is found. The amount of dislocation is also found in the copper matrix (marked by the white arrow). Figure 5b shows the SAED pattern of the copper matrix. It can be seen around the diffraction spots of the copper matrix, there are distributed extra diffraction spots with slightly darker contrast (marked by white circles). According to the similar study [21], the emergence of extra diffraction spots is due to the precipitation of $V$ element from copper matrix. Under higher magnification, the smaller $V$ nanoparticles (testified by EDS shown in Figure 5e) are detected with a size below $10 \mathrm{~nm}$ dispersed within the copper matrix, which is shown in Figure 5c. Figure $5 \mathrm{~d}$ shows the HRTEM image of the interface between $\mathrm{V}$ and $\mathrm{Cu}$ under the [112] zone axis of the copper matrix. It can be seen that $\mathrm{V}$ precipitates show parallel moire fringe in HRTEM. The measured fringe interval is $1.791 \mathrm{~nm}$ and its direction is parallel to the (200) plane of the matrix. The moire fringe 
is generated by interference between diffraction beams of two crystals with different lattice constants. Moire fringe interval (L) is the reciprocal of $\overrightarrow{\Delta a}$ which is the difference of vector diffraction $\overrightarrow{a_{1}}$ and $\overrightarrow{a_{2}}$, the direction of fringe is perpendicular to $\overrightarrow{\Delta a}$ and can be expressed as [22]

$$
\mathrm{L}=\frac{1}{|\overrightarrow{\Delta \mathrm{a}}|}=\frac{\mathrm{d}_{1} \mathrm{~d}_{2}}{\sqrt{\mathrm{d}_{1}^{2}+\mathrm{d}_{2}^{2}-2 \mathrm{~d}_{1} \mathrm{~d}_{2} \cos \theta}}
$$

where $\overrightarrow{a_{1}}$ is the direction of $(200)_{C u}, \overrightarrow{a_{2}}$ is the direction of $(110)_{V}, d_{1}$ is the interplanar distance of $\overrightarrow{a_{1}}$, $d_{2}$ is the interplanar distance of $\overrightarrow{a_{2}}$, and $\theta$ is the angle between $\overrightarrow{a_{1}}$ and $\overrightarrow{a_{2}} \cdot d_{1}, d_{2}$, and $\theta$ all can be measured and their value is $2.412 \mathrm{~nm}, 2.093 \mathrm{~nm}$, and $67.6^{\circ}$ respectively. Putting them into formula (1), the Moire fringe interval can be calculated and the result is $1.73 \mathrm{~nm}$ which is close to the measured value $(1.791 \mathrm{~nm})$. Observed under the HRTEM, the interface between $\mathrm{V}$ nanoparticle and matrix is clean and combined well.

It should be noted that the size of $\mathrm{V}$ nanoparticles presents a bimodal distribution after sintering according to the SEM and TEM observations. The range of $\mathrm{V}$ particle size is from several nanometers to hundreds of nanometers. According to Benghalem and Morris's view [23], the growth of V particles with a size smaller than $50 \mathrm{~nm}$ is due to the volume diffusion coarsening and the larger $\mathrm{V}$ particle is controlled by grain boundary diffusion.
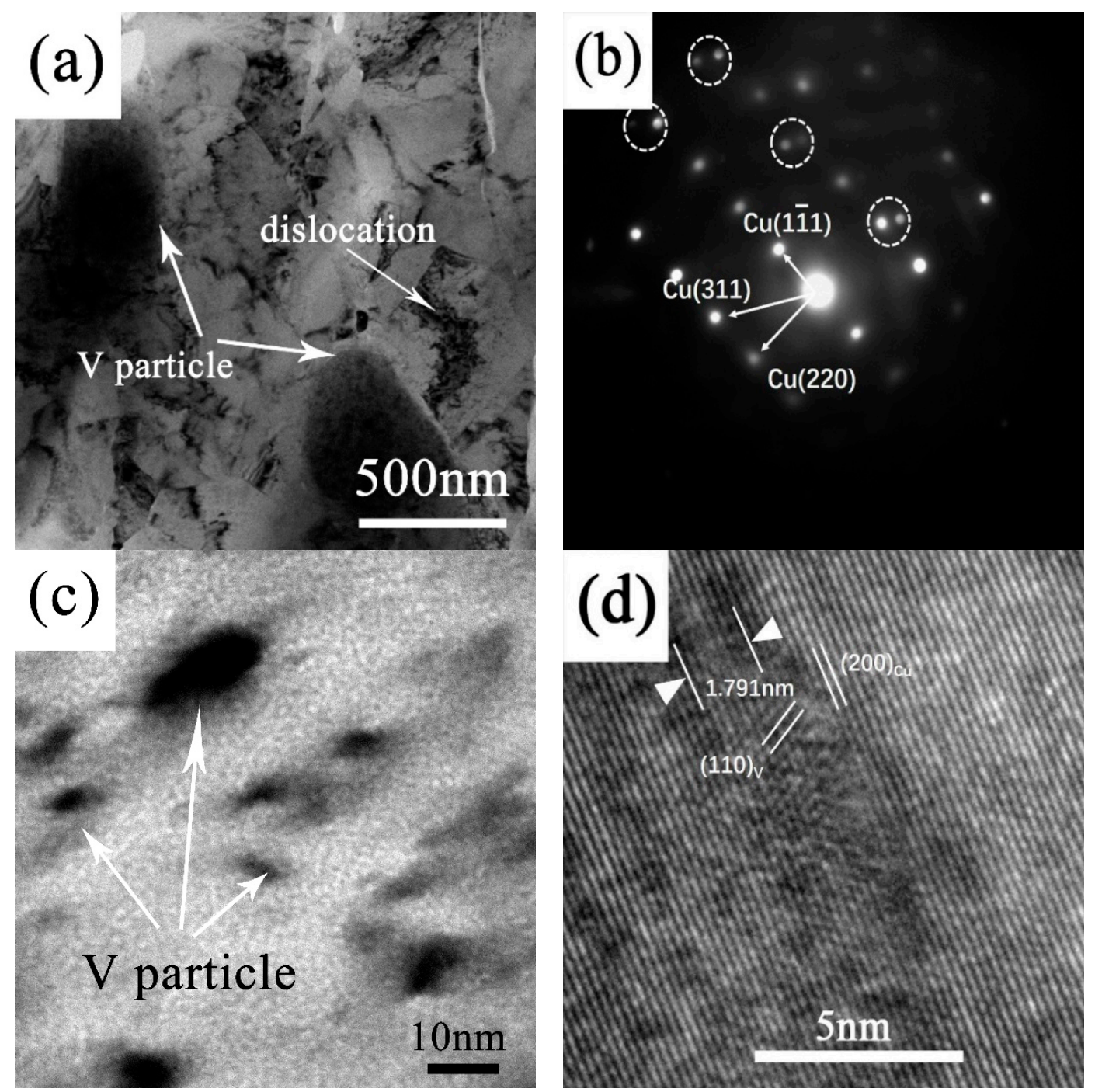

Figure 5. Cont. 


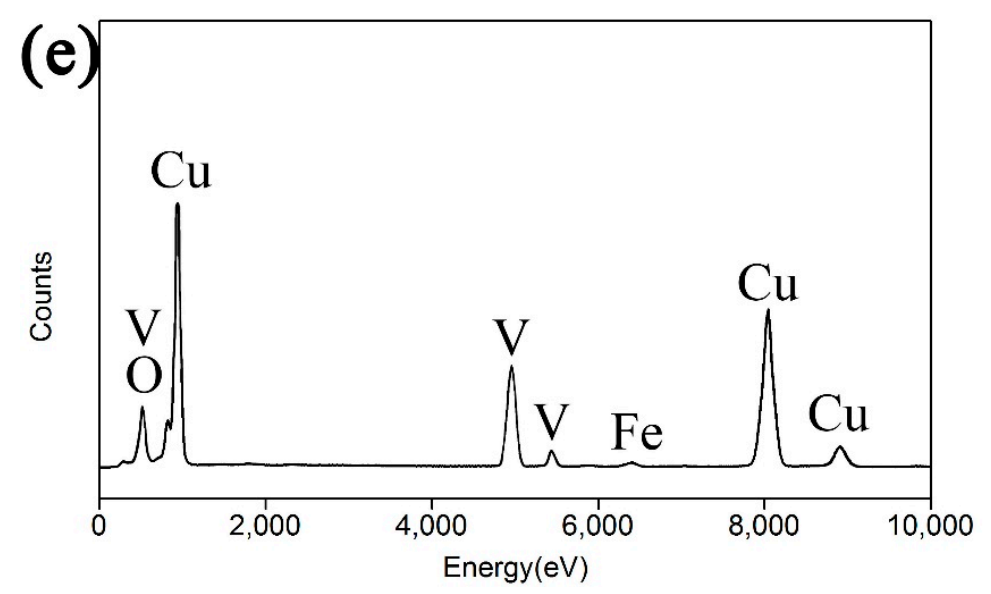

Figure 5. (a) TEM image of composite sintered at $900{ }^{\circ} \mathrm{C}$; (b) SAED pattern of copper matrix in (a); (c) BF image showing the nanosized V particles below $10 \mathrm{~nm}$; (d) HRTEM image of the interface between $\mathrm{V}$ and $\mathrm{Cu}$ and (e) the EDS result of the $\mathrm{V}$ particle in (c).

\subsection{Properties of Samples}

Figure $6 \mathrm{a}, \mathrm{b}$ shows the variation of microhardness, yield strength, and compressive strength of samples with the sintering temperature. It can be seen that increasing the sintering temperature could lead to the reduction of microhardness and the strength level. However, the sample sintered at $950{ }^{\circ} \mathrm{C}$ for $2 \mathrm{~h}$ still presents a high microhardness of $194 \mathrm{HV}$ and a high yield strength of $375 \mathrm{MPa}$. The engineering stress-strain curves of composites are shown in Figure 6c. It can be found that the toughness of composites increases with the sintering temperature, which is due to the increasing relative density. Figure 7 shows the conductivity of $\mathrm{Cu}-\mathrm{V}$ composites sintered at different temperatures. It can be found that the conductivity of $\mathrm{Cu}-\mathrm{V}$ composite increases with the increasing consolidation temperature, which is related to the increase of density of composite, growth of copper grain during the sintering, and the precipitation of $\mathrm{V}$ atoms from the copper matrix. These factors all can reduce the scattering of electrons and enhance the electrical conductivity. The conductivity of $\mathrm{Cu}-\mathrm{V}$ composite increases from $58.3 \%$ to $81.2 \%$ after increasing the temperature to $950{ }^{\circ} \mathrm{C}$. Therefore, $\mathrm{Cu}-2.4 \mathrm{wt} . \%$ possesses high strength and high conductivity simultaneously.
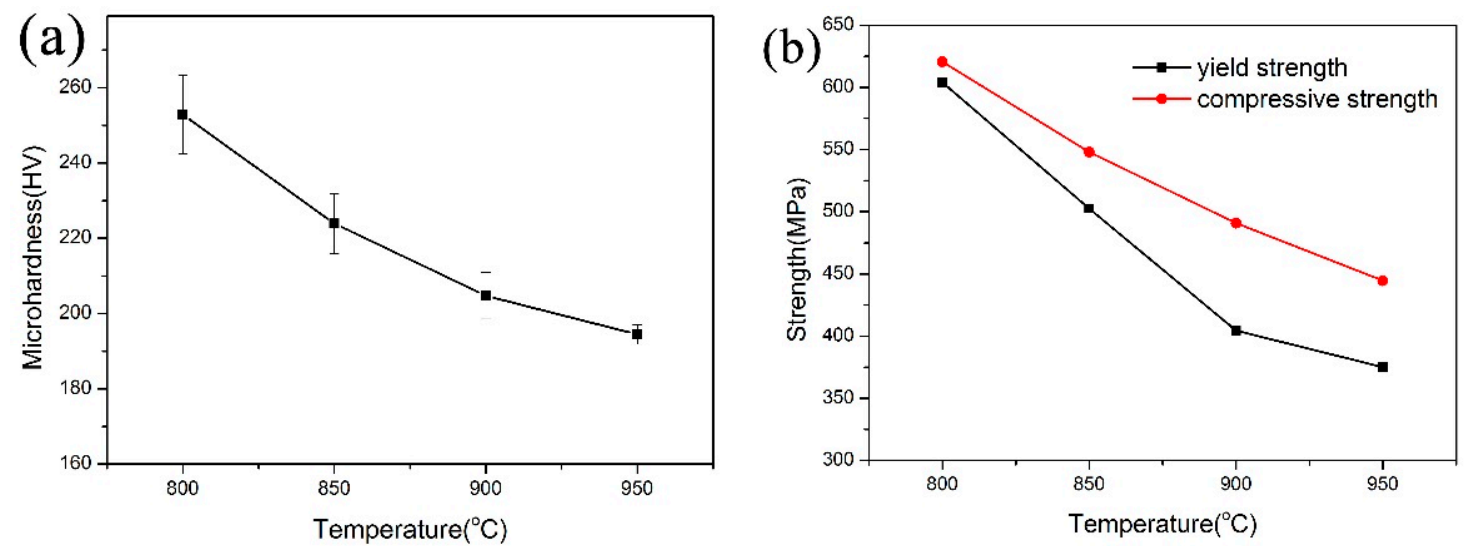

Figure 6. Cont. 


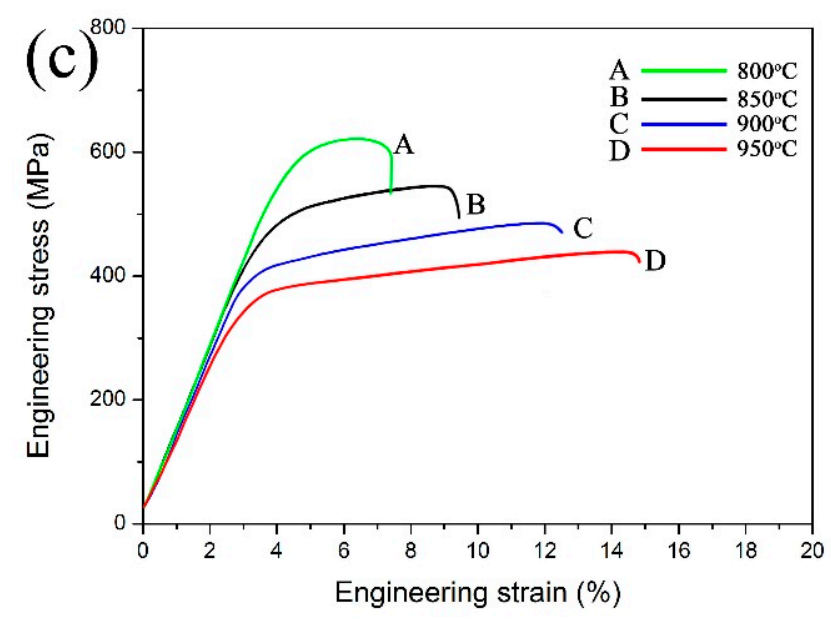

Figure 6. The changes of microhardness (a), yield strength and compressive strength (b) of composites with the sintering temperature; (c) engineering stress-strain curves of composites.

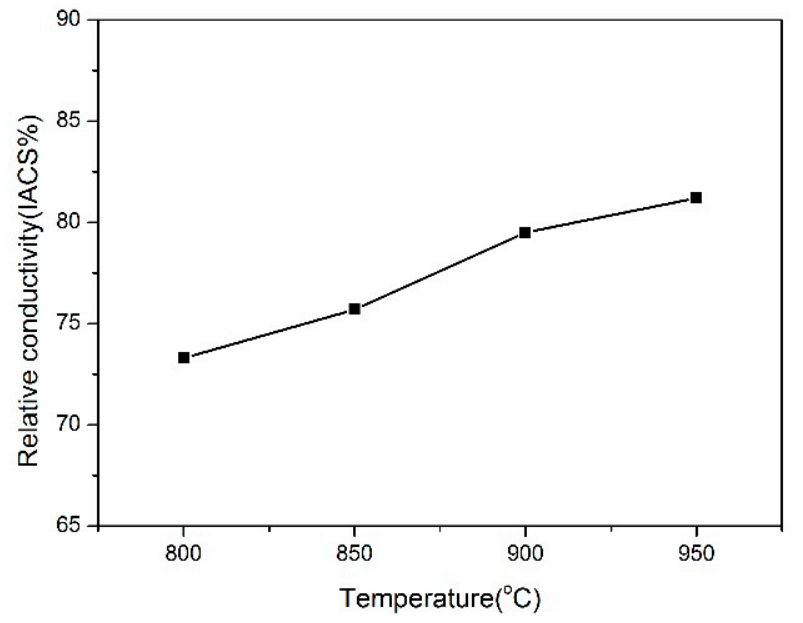

Figure 7. Conductivities of $\mathrm{Cu}-\mathrm{V}$ composites sintered at different temperatures.

\section{Discussion}

Following is the discussion of the strengthening mechanism of the $\mathrm{Cu}-\mathrm{V}$ composite. It is known that the property of metallic materials is mainly controlled by its microstructure, such as grain size, dislocations, second phases, solute atoms, and density, etc. for the $\mathrm{Cu}-\mathrm{V}$ composite in this study. Because $\mathrm{V}$ has no intermediate intermetallic phases and a minimum value of mutual solubility in copper matrix and can separate out easily at a relative high temperature, which could be verified by the clean lattice fringe of copper matrix (shown in Figure 5d), so the solution strengthening can also be neglected. The internal strain is decreased to a minimum level after sintering. Therefore, the strain strengthening is not significant here as well. However, the amount of dislocations is found existing in the $\mathrm{Cu}-\mathrm{V}$ composite (shown in Figure 5a). The dislocations effect each other and plenty of dislocations tangle and form a dislocation wall. V nanoparticles could hinder the movement of dislocation, so the precipitation strengthening via the Orowan mechanism should be considered. Because the $\mathrm{V}$ particle possesses very high hardness, it is difficult to shear by dislocations. So the Orowan mechanism of a dislocation-particle interaction mechanism is reasonable. The strength of $\Delta \sigma_{\text {Orowan }}$ can be expressed as [24]

$$
\Delta \sigma_{\text {Orowan }}=\frac{0.81 \mathrm{MGb}}{2 \pi(1-v)^{1 / 2}} \frac{\ln \pi r / 4 \mathrm{~b}}{r\left(\left(3 \pi / 2 f_{V}\right)^{1 / 2}-\pi / 4\right)}
$$


where $\mathrm{G}$ is the shear modulus of copper (45.5 GPa), $\mathrm{M}$ is the Taylor factor of copper (3.1), $\mathrm{b}$ is the Burgers vector of dislocations in copper $(0.255 \mathrm{~nm}), v$ is the Poisson's ratio of copper $(0.34), r$ is the $\mathrm{V}$ particle radius, $f_{V}$ is the volume fraction of the $V$ particle. According to the previous research [23], the strengthening effect of the particle with the size above $50 \mathrm{~nm}$ is little and can be neglected. However, the $f_{V}$ of $\mathrm{V}$ particles with size below $50 \mathrm{~nm}$ are difficult to count in TEM images because of the overlap and uncertainty of the thickness of the observation area. Allowing for the average size and the flat area of $\mathrm{V}$ particles with size above $50 \mathrm{~nm}$ can be measured from the SEM images and their volume fraction can be calculated subsequently. The total volume fraction of $\mathrm{V}$ particles is known. So the $f_{V}$ of $\mathrm{V}$ particles with size below $50 \mathrm{~nm}$ can be figured out. Counting and calculating, the $f_{V}$ of $\mathrm{V}$ particles with size below $50 \mathrm{~nm}$ in composite sintered at $800{ }^{\circ} \mathrm{C}, 850{ }^{\circ} \mathrm{C}, 900{ }^{\circ} \mathrm{C}$, and $950{ }^{\circ} \mathrm{C}$ is $2.1 \%, 1.9 \%, 1.4 \%$, and $1.2 \%$ respectively. The average size of $\mathrm{V}$ nanoparticle in the composite sintered at different temperature counted from TEM images is shown in Table 2. Taking these data into the formula (2), the value of $\Delta \sigma_{\text {Orowan }}$ can be calculated. The result is displayed in Table 2.

Table 2. Results of calculative $\Delta \sigma_{\text {Orowan }}$ and $\sigma_{\mathrm{H}-\mathrm{P}}$.

\begin{tabular}{|c|c|c|c|c|c|c|}
\hline $\begin{array}{c}\text { Consolidation } \\
\text { Temperature } \\
\left({ }^{\circ} \mathrm{C}\right)\end{array}$ & $\begin{array}{c}\text { Copper } \\
\text { Grain Size } \\
(\mathrm{nm})\end{array}$ & $\begin{array}{c}\text { V } \\
\text { Nanoparticle } \\
\text { Size (nm) }\end{array}$ & $\begin{array}{l}\text { V Nanoparticle } \\
\text { Content (vol.\%) }\end{array}$ & $\Delta \sigma_{\text {Orowan }}(\mathrm{MPa})$ & $\sigma_{\mathbf{H}-\mathbf{P}}(\mathbf{M P a})$ & $\begin{array}{c}\text { Yield } \\
\text { Strength } \\
\text { (MPa) }\end{array}$ \\
\hline 800 & 138 & 8.5 & 2.1 & 243.36 & 369.50 & 603.96 \\
\hline 850 & 186 & 10.4 & 1.6 & 185.77 & 322.29 & 502.55 \\
\hline 900 & 264 & 12.1 & 1.2 & 144.85 & 275.18 & 404.41 \\
\hline 950 & 285 & 13.8 & 0.9 & 114.63 & 265.94 & 374.84 \\
\hline
\end{tabular}

Comparing with the yield strength measured by experiment, the contribution of $\Delta \sigma_{\text {Orowan }}$ is not the main. So there must be other strengthening mechanism. Considering the grain boundary strengthening, the copper grain size was measured by XRD. The average copper grain size (shown in Table 2) for composite sintered at different temperature is $138 \mathrm{~nm}, 186 \mathrm{~nm}, 264 \mathrm{~nm}$, and $285 \mathrm{~nm}$ respectively. It can be seen that higher sintering temperature could lead to the coarsening of copper grain size dramatically, which is because the low content of $\mathrm{V}$ nanoparticles has limited hindering effects on copper grain growth. Generally, the contribution of fine crystal reinforcing should be analyzed based on the Hall-Petch relation [25]. Namely,

$$
\sigma_{\mathrm{H}-\mathrm{P}}=\sigma_{0}+\mathrm{k} d^{-1 / 2}
$$

where $\sigma_{0}$ is strength constant which controlled by grain structure and dislocation density, $\mathrm{k}$ is Hall-Petch coefficient, and d is grain size. Based on the Lei et al's report [14], the k of nano-crystalline copper is $4.0 \times 10^{3} \mathrm{MPa} / \mathrm{nm}^{1 / 2}$ and the $\sigma_{0}$ is $29 \mathrm{MPa}$. Through calculating, the results are shown in Table 2.

Through the above discussion, it can be found that the strength of $\mathrm{Cu}-\mathrm{V}$ composite is related to the grain boundary strengthening produced by nano-crystalline grains and the dispersion strengthening produced by $\mathrm{V}$ nanoparticles. It should be noted that the grain boundary strengthening mechanism plays the most important role.

\section{Conclusions}

In this study, Cu-2.4 wt.\%V nanocomposite has been prepared by mechanical alloy and vacuum hot-pressed sintering technology. The microstructure and properties have been observed and analysed. The conclusions are as follows.

(1) With the increasing sintering temperature, the density and conductivity of Cu-2.4 wt.\%V composite increase, while the microhardness and yield strength reduce gradually, which is mainly due to the growth of copper grain size. 
(2) $\mathrm{Cu}-2.4$ wt.\%V nanocomposite presents high strength and high electrical conductivity. The composite sintered at $900{ }^{\circ} \mathrm{C}$ has a microhardness of $205 \mathrm{HV}$, a yield strength of $404.41 \mathrm{MPa}$, and an electrical conductivity of $79.5 \%$ IACS.

(3) After sintering, copper grain size and V nanoparticle both maintain in nanoscale; the strengthening mechanism is related to the grain boundary strengthening and dispersion strengthening, while the grain boundary strengthening mechanism plays the most important role.

Author Contributions: Conceptualization, Y.W. (Yong Wang) and X.R.; Data curation, Y.W. (Yong Wang), H.Z., and Y.W. (Yutong Wang); Formal analysis, X.R. and J.W.; Investigation, Y.W. (Yong Wang) and H.Z.; Writing—original draft, Y.W. (Yong Wang); Writing—review \& editing, J.W.

Funding: This project is supported by National Natural Science Foundation of China (Grant No. 51874043 and No. 51805046).

Conflicts of Interest: The authors declared no conflicts of interest.

\section{References}

1. Murashkin, M.Y.; Sabirov, I.; Sauvage, X.; Valiev, R.Z. Nanostructured Al and Cu alloys with superior strength and electrical conductivity. J. Mater. Sci. 2016, 51, 33-49. [CrossRef]

2. Popovich, A.; Sufiiarov, V.; Polozov, I.; Borisov, E.; Masaylo, D.; Orlov, A. Microstructure and mechanical properties of additive manufactured copper alloy. Mater. Lett. 2016, 179, 38-41. [CrossRef]

3. YTian, Z.; Zhao, L.J.; Park, N.; Liu, R.; Zhang, P.; Zhang, Z.J.; Shibata, A.; Zhang, Z.F.; Tsuji, N. Revealing the deformation mechanisms of $\mathrm{Cu}-\mathrm{Al}$ alloys with high strength and good ductility. Acta Mater. 2016, 110, 61-72.

4. Li, A.; Szlufarska, I. Morphology and mechanical properties of nanocrystalline Cu/Ag alloy. J. Mater. Sci. 2017, 52, 4555-4567. [CrossRef]

5. Shen, D.P.; Zhu, Y.J.; Yang, X.; Tong, W.P. Investigation on the microstructure and properties of Cu-Cr alloy prepared by in-situ synthesis method. Vacuum 2018, 149, 207-213. [CrossRef]

6. Wei, H.; Cui, Y.C.; Cui, H.Q.; Wei, Y.H.; Hou, L.F. Effects of multiple trace alloying elements on the microstructure and properties of Cu-4 wt.\% Ti alloys. Mater. Sci. Eng. A 2017, 707, 392-398. [CrossRef]

7. Shadkam, A.; Sinclair, C.W. The coupled effect of grain size and solute on work hardening of $\mathrm{Cu}-\mathrm{Ni}$ alloys. Philos. Mag. Lett. 2015, 95, 555-563. [CrossRef]

8. Lee, S.; Matsunaga, H.; Sauvage, X.; Horita, Z. Strengthening of Cu-Ni-Si alloy using high-pressure torsion and aging. Mater. Charact. 2014, 90, 62-70. [CrossRef]

9. Islamgaliev, R.K.; Nesterov, K.M.; Bourgon, J.; Champion, Y.; Valiev, R.Z. Nanostructured Cu-Cr alloy with high strength and electrical conductivity. J. Appl. Phys. 2014, 115, 194301. [CrossRef]

10. Zuo, X.; Zhu, J.; An, B.; Han, K.; Han, K.; Han, K. Influence of Fe addition on microstructure and properties of Cu-Ag composite. Met. Mater. Int. 2017, 23, 974-983. [CrossRef]

11. Kardani, A.; Montazeri, A. Temperature-based plastic deformation mechanism of Cu/Ag nanocomposites: A molecular dynamics study. Comput. Mater. Sci. 2018, 144, 223-231. [CrossRef]

12. Rabiee, M.; Mirzadeh, H.; Ataie, A. Processing of $\mathrm{Cu}-\mathrm{Fe}$ and $\mathrm{Cu}-\mathrm{Fe}-\mathrm{SiC}$ nanocomposites by mechanical alloying. Adv. Powder Technol. 2017, 28, 1882-1887. [CrossRef]

13. Hong, S.I.; Hill, M.A. Microstructureal stability of $\mathrm{Cu}-\mathrm{Nb}$ microcompotite wires fabricated by the bundling and drawing process. Mater. Sci. Eng. A 2000, 281, 189-197. [CrossRef]

14. Lei, R.S.; Xu, S.Q.; Wang, M.P.; Wang, H.P. Microstructure and properties of nanocrystalline copper-niobium alloy with high strength and high conductivity. Mater. Sci. Eng. A 2013, 586, 367-373. [CrossRef]

15. Pantsyrnyi, V.I.; Drobyshev, V.A.; Khlebova, N.E.; Kukina, O.D.; Zinov'ev, V.G.; Zurabov, V.S. Microstructure of cast ingots of $\mathrm{Cu}-\mathrm{V}$ alloys after vacuum melting by different methods. Met. Sci. Heat Treat. 2011, 53, 176. [CrossRef]

16. Pantsyrny, V.I.; Khlebova, N.E.; Sudyev, S.V.; Kukina, O.V.; Beliakov, N.A.; Polikarpova, M.V. Thermal Stability of the High Strength High Conductivity $\mathrm{Cu}-\mathrm{Nb}, \mathrm{Cu}-\mathrm{V}$, and $\mathrm{Cu}-\mathrm{Fe}$ Nanostructured Microcomposite Wires. IEEE Trans. Appl. Supercond. 2014, 24, 1-4. [CrossRef] 
17. Pantsyrny, V.; Shikov, A.; Khlebova, N.; Drobishev, V.; Kozlenkova, N.; Polikarpova, M.; Belyakov, N.; Kukina, O. The Nanostructured High Strength High Conductivity Cu Matrix Composites with Different BCC Metals Strengthening Filaments. IEEE Trans. Appl. Supercond. 2010, 20, 1614-1618. [CrossRef]

18. Nikulin, S.A.; Rogachev, S.O.; Rozhnov, A.B.; Pantsyrnyi, V.I.; Khlebova, N.E.; Nechaykina, T.A.; Khatkevich, V.M.; Zadorozhnyy, M.Y. Microstructure and fatigue strength of high-strength $\mathrm{Cu}-\mathrm{Fe}$ and $\mathrm{Cu}-\mathrm{V}$ in-situ nanocomposite wires. Compos. Part B 2015, 70, 92-98. [CrossRef]

19. Zeng, L.F.; Gao, R.; Xie, Z.M.; Miao, S.; Fang, Q.F.; Wang, X.P.; Zhang, T.; Liu, C.S. Development of interface-dominant bulk $\mathrm{Cu} / \mathrm{V}$ nanolamellar composites by cross accumulative roll bonding. Sci. Rep. 2017, 7, 40742. [CrossRef] [PubMed]

20. Suryanarayana, C. Mechanical alloying and milling. Prog. Mater. Sci. 2001, 46, 1-184. [CrossRef]

21. Watanabe, D.; Watanabe, C.; Monzen, R. Determination of the interface energies of spherical, cuboidal and octahedral face-centered cubic precipitates in $\mathrm{Cu}-\mathrm{Co}, \mathrm{Cu}-\mathrm{Co}-\mathrm{Fe}$ and $\mathrm{Cu}-\mathrm{Fe}$ alloys. Acta Mater. 2009, 57, 1899-1911. [CrossRef]

22. Fujii, T.; Nakazawa, H.; Kato, M.; Dahmen, U. Crystallography and morphology of nanosized Cr particles in a Cu-0.2\% Cr alloy. Acta Mater. 2000, 48, 1033-1045. [CrossRef]

23. Benghalem, A.; Morris, D.G. Microstructure and mechanical properties of concentrated copper-niobium alloys prepared by mechanical alloying. Mater. Sci. Eng. A 1993, 161, 255-266. [CrossRef]

24. Chen, B.A.; Pan, L.; Wang, R.H.; Liu, G.; Cheng, P.M.; Xiao, L.; Sun, J. Effect of solution treatment on precipitation behaviors and age hardening response of $\mathrm{Al}-\mathrm{Cu}$ alloys with $\mathrm{Sc}$ addition. Mater. Sci. Eng. A 2011, 530, 607-617. [CrossRef]

25. Benson, D.J.; Fu, H.; Meyers, M.A. On the effect of grain size on yield stress: Extension into nanocrystalline domain. Mater. Sci. Eng. A 2001, 319-321, 854-861. [CrossRef]

(C) 2019 by the authors. Licensee MDPI, Basel, Switzerland. This article is an open access article distributed under the terms and conditions of the Creative Commons Attribution (CC BY) license (http:/ / creativecommons.org/licenses/by/4.0/). 